\title{
Residual Stresses in Dengeling-Treated Aluminum Alloy AA 7050
}

\author{
Linnéa Selegård ${ }^{1, a}$, Ru Lin Peng ${ }^{2, b^{*}}$, Annethe Billenius $^{2, c}$, Gert Petersén ${ }^{1, d}$, \\ Markus ESS ${ }^{3, \mathrm{e}}$, Mattias Jonsson ${ }^{1, \mathrm{f}}$ \\ ${ }^{1}$ Saab Aeronautics, S-58188 Linköping, Sweden \\ 2Dept of Management and Engineering, Linköping University, SE-581 83 Linköping, Sweden \\ ${ }^{3}$ Starrag AG, Seebleichestrasse 61, 9404 Rorschacherberg, Switzerland \\ alinnea.selegard@saabgroup.com, bru.peng@liu.se, ${ }^{\mathrm{c}}$ annethe.billenius@liu.se \\ dgert.petersen@saabgroup.com, ${ }^{\mathrm{e}}$ markus.ess@starrag.com, \\ fmattias.jonsson2@saabgroup.com \\ * corresponding author
}

\begin{abstract}
Keywords: Dengeling, Mechanical Surface Treatment, Aluminum Alloy, Residual Stress, Roughness
\end{abstract}

\begin{abstract}
Dengeling is a new method for mechanical surface treatment of metallic parts to enhance fatigue properties. The treatment produces consecutive lines of indents by a spherical indenter, resulting in compressive residual stresses in a surface layer. This paper investigated residual stresses, surface roughness and near surface deformation, in specimens of AA 7050 T7451 after different dengeling treatments. The effect of indent overlap $(0 \%, 25 \%$ and $50 \%)$ and indenter size $(\varnothing 3$ and $\varnothing 8$ $\mathrm{mm})$ were studied. X-Ray diffraction measurements revealed that plastic deformation and compressive residual stresses were generated in a surface layer of about $1 \mathrm{~mm}$ by treatments using the $\varnothing 3 \mathrm{~mm}$ indenter and about $1.2 \mathrm{~mm}$ by treatment using the $\varnothing 8 \mathrm{~mm}$ indenter. Anisotropic residual stress fields were observed with higher compressive residual stresses (-360 MPa for $50 \%$ indent overlap, independent of indenter size) perpendicular to indent lines and lower (max -270 MPa for all the treatments) parallel to indent lines. Increasing the overlap between indents gave higher subsurface compressive residual stresses only in the transverse direction of indent lines. It also reduced the surface roughness. Best surface finish (Ra below $1 \mu \mathrm{m}$ ) was obtained when using the $\emptyset 8$ $\mathrm{mm}$ indenter and $50 \%$ indent overlap.
\end{abstract}

\section{Introduction}

Dengeling is a new method for mechanical surface treatment of metallic parts to enhance fatigue properties. The treatment is carried out on a numerically controlled machine using a special indenter which moves and strikes the surface of the metal part in a given pattern and at a high frequency, up to $600 \mathrm{~Hz}$. The transfer of kinetic energy from the indenter upon impact causes in-plane plastic deformation, producing consecutive lines of indents in the treated surface. Similar to the widely used shot peening process in which the surface is bombarded by hard shots, the dengeling treatment induces compressive residual stresses in a surface layer. As a considerable number of publications on shot peening have demonstrated [1-3], compressive stresses in near surface regions can greatly improve the fatigue resistance of a part. Dengeling has certain benefits over shot peening. The process is $\mathrm{NC}$ controlled, thus the operator can control exactly the location and magnitude of the generated residual stresses. Furthermore, the dengeling treatment is performed on the same machine that is used for machining the part; it can therefore be integrated into the machining process of metallic parts. That machining and surface mechanical treatment are carried out on the same machine means a great reduction of production cycle time and cost.

(c) (1) Content from this work may be used under the terms of the Creative Commons Attribution 3.0 license. Any further distribution of this work must maintain attribution to the author(s) and the title of the work, journal citation and DOI. Published under license by Materials Research Forum LLC. 
Process parameters, including the diameter of indenter, center-to-center distances between neighboring dimples, and stroke distance of the indenter, can be controlled in a dengeling treatment to vary the induced surface modification such as surface roughness, depth distributions of residual stresses, and near surface hardness. Such surface changes are considered to be important for the fatigue performance of the treated part, as researches with respect to shot peening have shown $[4,5]$. However, little knowledge exists, which relates the treatment results to the dengeling process parameters used. The purpose of the current work is to characterize depth distribution of residual stress, surface roughness, and subsurface deformation in dengeling treated specimens of aluminum alloy 7050 in T7451 condition with regard to the effect of overlap between dimples and indenter size.

\section{Experimental details}

Materials and Dengeling treatment. A $6 \mathrm{~cm}$ thick plate of aluminum alloy, AA 7050 in T7451 condition, was used. Before the dengeling treatment, the plate surfaces were levelled by milling, which induced a surface residual stress of $33 \pm 21.7 \mathrm{MPa}$ in the cutting direction and $-135.9 \pm 9.7 \mathrm{MPa}$ in the transverse direction. The XRD measurements for residual stresses also revealed plastic deformation in a surface layer of about $50 \mu \mathrm{m}$.

The dengeling treatments were performed by producing consecutive lines of indents on the milled surfaces. The process parameters were selected to show the influence of coverage rate and indenter size while the indenting frequency, $200 \mathrm{~Hz}$, and stroke distance, $0.5 \mathrm{~mm}$, remained unchanged. Two indenter sizes, one $3 \mathrm{~mm}$ and the other $8 \mathrm{~mm}$ in diameter, were used. As can be seen in Table 1, the diameter of dimples produced by the smaller indenter was $0.75 \mathrm{~mm}$ and for the larger indenter 0.72 $\mathrm{mm}$. The center-to-center distance between dimples in the moving direction of the indenter was used to calculate overlapping rate between dimples. They were $0 \%, 25 \%$ and $50 \%$ as given in the last column of Table 1. The line feed defining the distance between neighboring lines of dimples was approximately equal to the selected dimple distance.

Table 1 Dengeling process parameters

\begin{tabular}{|c|c|l|c|l|l|l|}
\hline Specimen & $\begin{array}{l}\text { Feed rate } \\
(\mathrm{mm} / \mathrm{min})\end{array}$ & $\begin{array}{l}\text { Indenter } \\
\text { diameter } \\
(\mathrm{mm})\end{array}$ & $\begin{array}{l}\text { Dimple } \\
\text { diameter } \\
(\mathrm{mm})\end{array}$ & $\begin{array}{l}\text { Line feed } \\
(\mathrm{mm} / \text { line })\end{array}$ & $\begin{array}{l}\text { Dimple } \\
\text { distance } \\
(\mathrm{mm})\end{array}$ & $\begin{array}{l}\text { Dimple } \\
\text { overlap (\%) }\end{array}$ \\
\hline S1 & 9000 & 3 & 0.75 & 0.760 & 0.7500 & 0 \\
\hline S2 & 6750 & 3 & 0.75 & 0.559 & 0.5625 & 25 \\
\hline S3 & 4500 & 3 & 0.75 & 0.380 & 0.3750 & 50 \\
\hline S4 & 4320 & 8 & 0.72 & 0.369 & 0.3600 & 50 \\
\hline
\end{tabular}

Characterization experiments. Residual stress measurements were performed using the standard $\sin ^{2} \psi$ method [6] with $9 \psi$-angles spreading between $\pm 55^{\circ}$. Diffraction peaks from the $\{311\}$ lattice planes of $\mathrm{Al}$ were measured using the $\mathrm{Cr}-\mathrm{K} \alpha$ radiation and the $\mathrm{X}$-Ray elastic constant for residual stress calculation was $\frac{1}{2} S_{2}=19.54 \mathrm{MPa}^{-1}$. Residual stresses parallel to the indent lines (LD) and the line feed direction (LFD) were determined. As they showed a significant difference, residual stresses in the $45^{\circ}$ direction with respect to LD were also investigated. Layer removal by electrolytic polishing was employed to facilitate measurements of in-depth residual stresses and thus the desired depth profiles could be obtained. No correction was made for possible stress relaxation due to the electrolytic polishing.

A cross-section cut in $75^{\circ}$ to LD was prepared for each specimen for examination in Optical Microscope (OM) and Scanning Electron Microscope (SEM) to investigate changes in surface topography and microstructure after the dengeling treatments.

\section{Results and discussions}

Surface roughness and deformation. Vertical lines of indents with a difference in overlap between the indents within the lines and between the lines are clearly identified in the optical micrographs in Fig. 1. At $0 \%$ dimple overlap, the S1 surface was not fully covered by dimples; a 
calculation using the geometry values in Table 1 gave a theoretical area coverage of $78.5 \%$. An almost full area coverage was observed for S2 which was treated with $25 \%$ dimple overlap. When the $\emptyset 8 \mathrm{~mm}$ indenter was used (S4), the produced indents seem to be much shallower; a comparison to the milled surface confirmed that marks from the milling operation were still visible on the surface.

Results from the profilometer measurements were listed in Table 2. A small difference between the measurements along LD $(\mathrm{Ra}, \mathrm{LD})$ and $\mathrm{LFD}(\mathrm{Ra}, \mathrm{LFD})$ was related to the different arrangements of indents in the two directions. With a decreased dimple distance from $0 \%$ to $50 \%$ overlap, Ra,LD was reduced almost by half, from $8.6 \mu \mathrm{m}$ to $4.45 \mu \mathrm{m}$, while Ra, $\mathrm{LFD}$ was decreased from $6.5 \mu \mathrm{m}$ to $4.8 \mu \mathrm{m}$. The use of the large indenter (S4) with an overlap of 50\% resulted in very fine surface roughness with a Ra below $1 \mu \mathrm{m}$. Micrographs of the $75^{\circ}$ cross-sections were compared in Fig. 2, which showed the evolution of the surface towards a more homogenous profile when the dimple overlap was increased. Roughness parameters, Ra and Rz, estimated from 4 micrographs (a total width of about 8 $\mathrm{mm}$ ) over the cross-section of each specimen were also shown in Table 2. Except for S1 which had too few indents for the OM measurements, the obtained Ra values were similar to those from the profilometer measurements.
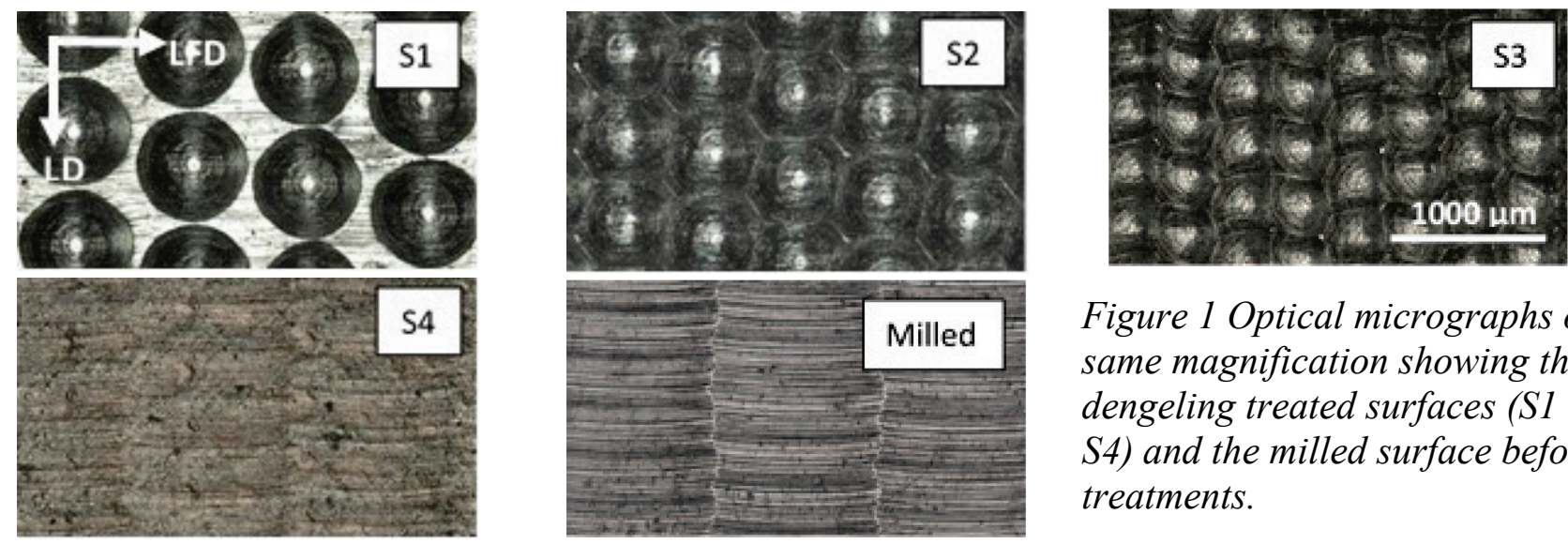

Figure 1 Optical micrographs of same magnification showing the dengeling treated surfaces (S1 to S4) and the milled surface before treatments.

Table 2 Surface roughness measured on surface $(R a, L D, R a, L F D)$ and on cross-sections $(R a, R z)$

\begin{tabular}{|c|c|c|c|c|}
\hline & $\mathrm{S} 1$ & $\mathrm{~S} 2$ & $\mathrm{~S} 3$ & $\mathrm{~S} 4$ \\
\hline $\mathrm{Ra}, \mathrm{LD}(\mu \mathrm{m})$ & 8.60 & 6.28 & 4.45 & 0.92 \\
\hline $\mathrm{Ra}, \mathrm{LFD}(\mu \mathrm{m})$ & 6.50 & 6.35 & 4.80 & 0.73 \\
\hline $\mathrm{Ra}(\mu \mathrm{m})$ & $5.71 \pm 1.29$ & $7.12 \pm 0.40$ & $4.94 \pm 0.38$ & $0.84 \pm 0.28$ \\
\hline $\mathrm{Rz}(\mu \mathrm{m})$ & $26.82 \pm 6.24$ & $30.58 \pm 2.47$ & $22.92 \pm 3.03$ & $5.87 \pm 2.01$ \\
\hline
\end{tabular}
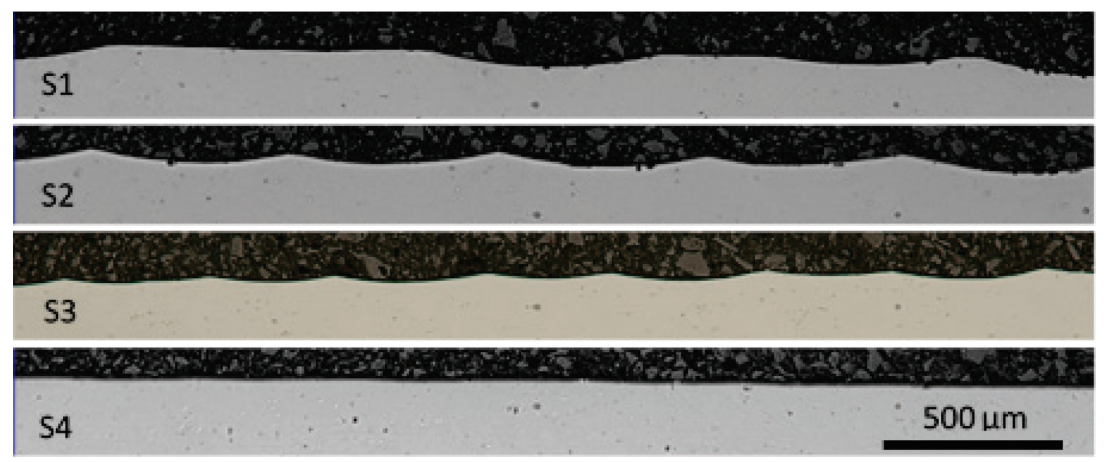

Figure 2 Surface roughness profile became more homogeneous with increased dimple overlapping: $0 \%$ (S1), 25\% (S2) and 50\% (S3). $S 4$ with the $\emptyset 8 \mathrm{~mm}$ indenter and $50 \%$ overlap

gave a very fine surface finishing.

Plastic deformation in the treated surface layer was studied by electron channeling contrast imaging in SEM and some images were shown in Fig. 3 as examples. A direct comparison between the specimens was not trivial; the small grains in the material requires examinations under high 
magnification while the surface profile varies in sub-millimeter scale and the deformation extends to a millimeter depth. Nevertheless, it was revealed that plastic deformation occurred not only close to the surface under dimples but also in the regions between dimples. It was also shown that the $\emptyset 8 \mathrm{~mm}$ indenter produced a more gentle effect on the surface; the near surface plastic deformation appeared to be lower (S4 in Fig. 3) than that in the treatment using the $\varnothing 3 \mathrm{~mm}$ indenter (S3 in Fig. 3), evident by the stronger strain contrast in S3.
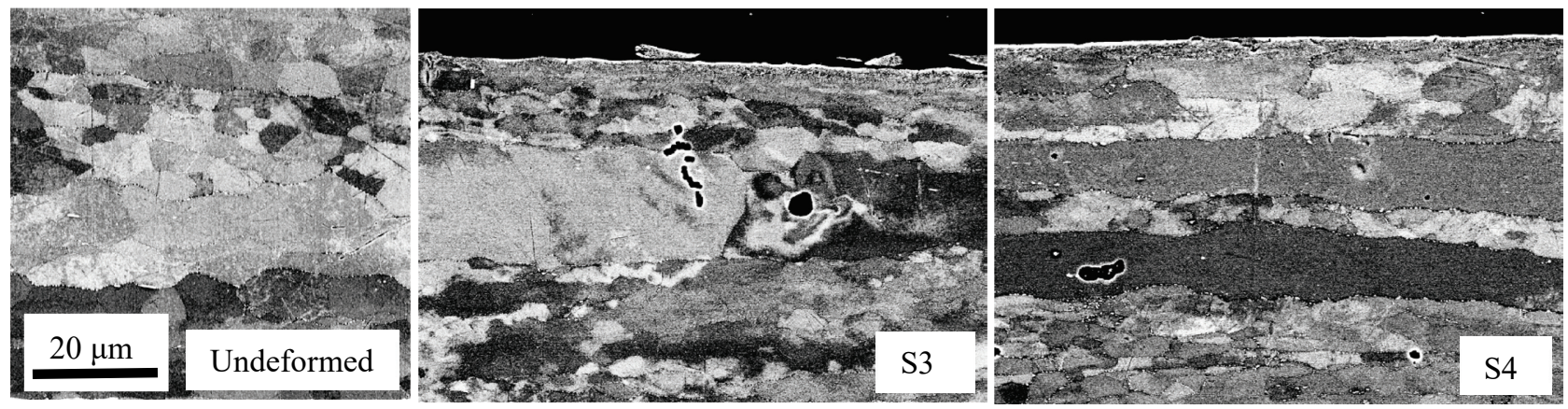

Figure 3 Backscatter electron images of same magnification showing stronger strain contrasts in $S 3$ than in S4, indicating that the small indenter induced larger plastic deformation in the near surface region.

Residual stresses. The employed dengeling treatments were found to have induced compressive residual stresses in a significant depth, about $1 \mathrm{~mm}$ when using the $\emptyset 3 \mathrm{~mm}$ indenter and $1.2 \mathrm{~mm}$ for the $\varnothing 8 \mathrm{~mm}$ indenter. Typical depth-profiles of residual stresses can be seen in Fig. 4. For this particular specimen treated using the $\emptyset 3 \mathrm{~mm}$ indenter and $50 \%$ dimple overlap, the surface residual stresses were measured to be $-198.6 \pm 5.8$ and $-301.8 \pm 14.3$ for the LD and LFD directions, respectively. The residual stresses in the $45^{\circ}$ direction were in between the LD and LFD stresses. About 100 to $400 \mu \mathrm{m}$ below the surface, all the three stress components showed a maximum stress level with the highest compressive stress values, $-273 \mathrm{MPa}$ in the LD and $-356 \mathrm{MPa}$ in the LFD direction. At the $1 \mathrm{~mm}$ depth, the residual stress profiles changed to low tensile values. The thicknesses of the surface compression layers from the dengeling treatments studied here appear to be large, about two to four times of that commonly found for shot peened high strength aluminum alloys, see for example [3-5]. The large penetration depth of the dengeling treatment could partly be explained by a more efficient transfer of kinetic energy from the indenter to the part surface, in comparison with shot peening in which free bouncing of the shots are allowed. Another feature distinct from shot peening is a significant difference between the in-plane stress components; higher compressive residual stresses appeared in the LFD than in the LD direction. The largest difference, about $100 \mathrm{MPa}$, was in the surface, which sustained up to the $400 \mu \mathrm{m}$ depth. The same trend existed for the other specimens, see Fig. 5 and Fig. 6, the difference between the LD and LFD stresses was however smaller for the S1 and S2 specimens with a lower overlapping rate of dimples. This stress anisotropy can be related to an anisotropic in-plane plastic deformation as the dengeling treatment was carried out by producing lines of indents.

Broadening of the diffraction peaks is related to the amount of plastic strain in the measured volume. As the peak width profile (PW) in Fig. 4 indicated, the plastic deformation penetrated to almost the same depth as the compressive stresses. It should be noted that the subsurface residual stress plateau corresponds to a small plastic deformation gradient in the region and the compressive residual stresses dropped as the plastic deformation decreased more rapidly at the larger depth. 


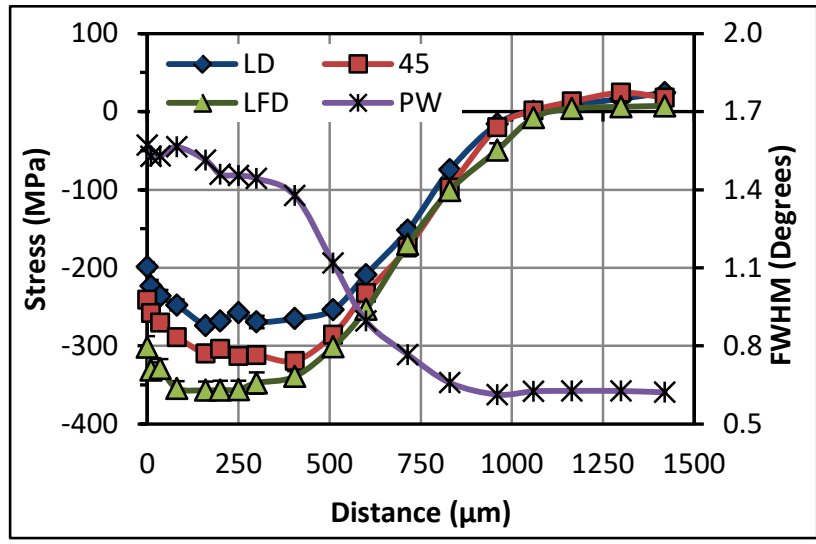

Figure 4 Depth profiles of residual stresses measured in $S 3$ treated using a $\emptyset 3 \mathrm{~mm}$ indenter, $0.5 \mathrm{~mm}$ stroke distance and $50 \%$ overlapping. LD: line direction; LFD: line feed direction; 45: $45^{\circ}$ to $L D ; P W$ : peak width as FWHM. The lines are guide to the eye.
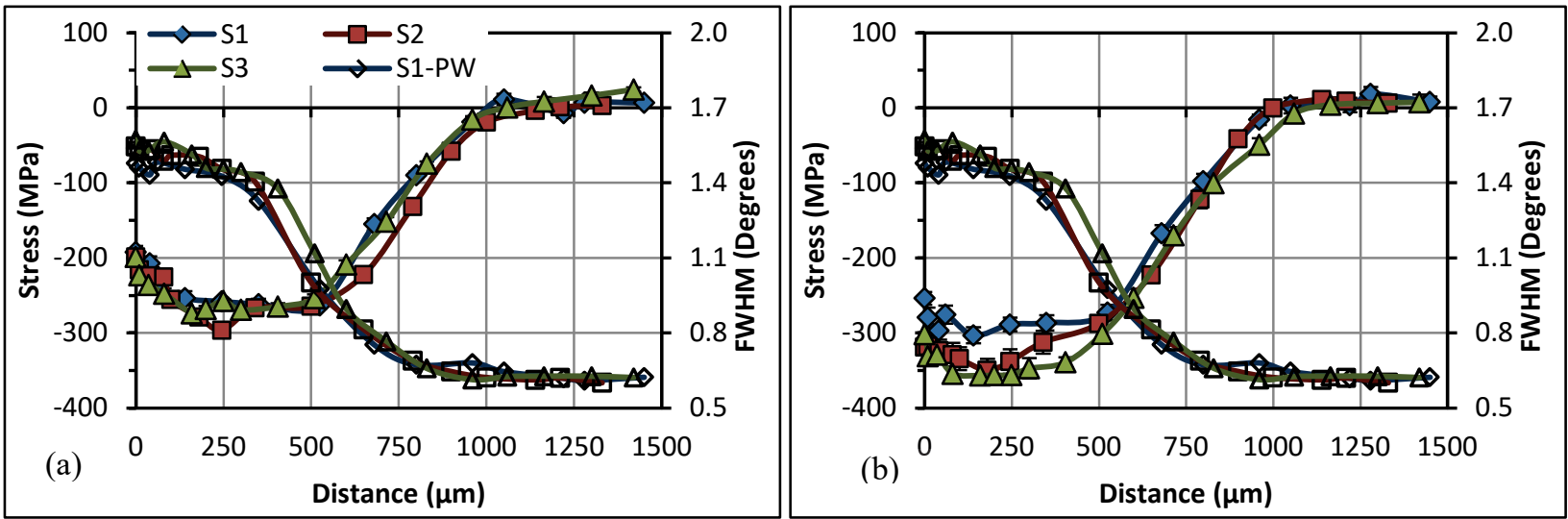

Figure 5 Influence of dimple overlapping with $0 \%$ (S1), 25\% (S2) and 50\% (S3) on residual stresses. (a) Residual stresses parallel to the LD direction and (b) residual stresses in the LFD direction. The lines are guide to the eye.
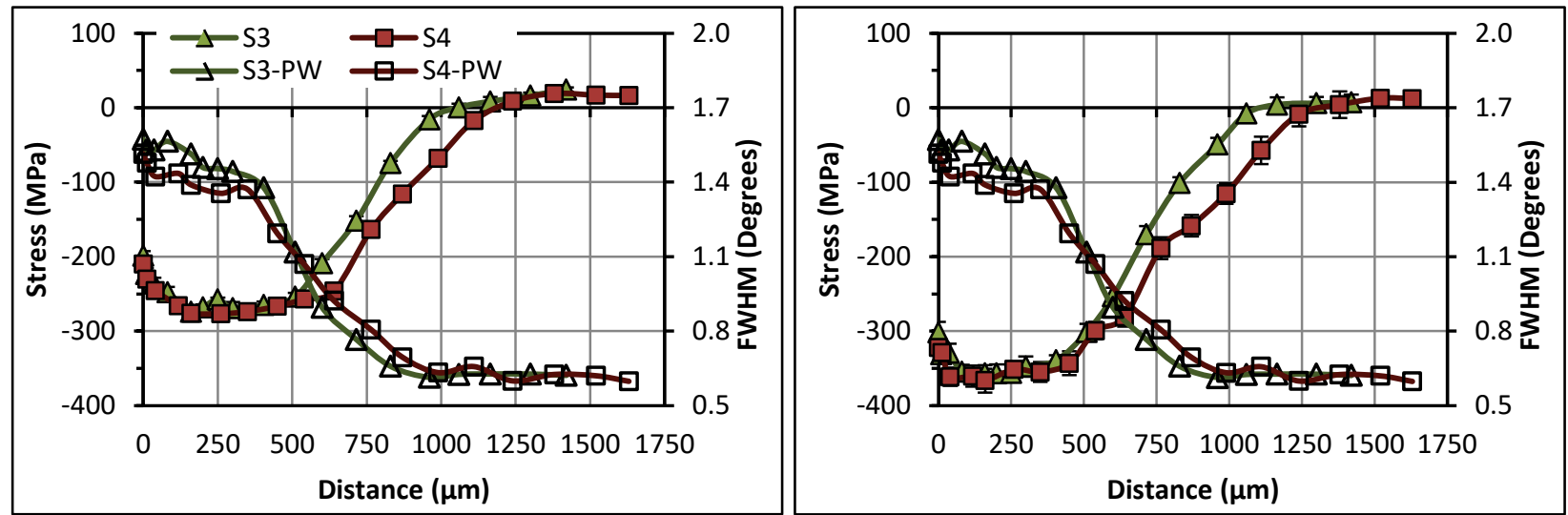

Figure 6 Influence of indenter size, $\emptyset 3 \mathrm{~mm}(\mathrm{~S} 3)$ and $\varnothing 8 \mathrm{~mm}$ (S4), on residual stresses. (a) Residual stresses parallel to indent lines, (b) perpendicular to indent lines. The lines are guide to the eye.

The influence of overlap between dimples was illustrated in Fig. 5 where residual stress profiles were compared for specimens treated using different dimple distances while the indenter diameter $(\varnothing 3 \mathrm{~mm})$ and stroke distance $(0.5 \mathrm{~mm})$ were the same. As Fig. 5(a) showed, the residual stresses parallel to the LD direction was essentially the same independent of dimple overlap. In the LFD direction, however, an increase of dimple overlap from $0 \%(\mathrm{~S} 1)$ to $25 \%(\mathrm{~S} 2)$ resulted in higher 
surface and subsurface compressive residual stresses although a further increase from $25 \%$ to $50 \%$ (S3) overlap produced a smaller effect. As a result of increased LFD stress, the stress anisotropy increased with increased dimple overlap as aforementioned. The surface and subsurface plastic deformations were also increased slightly for a higher overlapping rate, which might be the cause of higher compressive residual stresses in the LFD direction. However, the dimple overlap had little effect on the depth of plastic deformation and compressive residual stresses; it was approximately 1 $\mathrm{mm}$ for all the three specimens shown in Fig. 5.

In terms of the influence of indenter size, Fig. 6 revealed that a larger depth of compressive residual stresses was induced by treatment using the $\emptyset 8 \mathrm{~mm}$ indenter (S4) while the surface and subsurface compressive residual stresses did not seem to vary much with the indenter size. The effect on the plastic deformation was obvious: the $\varnothing 8 \mathrm{~mm}$ indenter gave a larger deformation depth but somewhat less surface and subsurface deformation which agrees with the lower subsurface deformation observed in SEM (Fig. 3).

\section{Summary}

Dengeling treatments with different dimple overlap and indenter size were performed on an aluminium alloy, AA 7050 T7451. The treatments were observed to induce compressive residual stresses to a significant depth, $1 \mathrm{~mm}$ or larger, which is two to four time of that for conventional shot peening of high strength aluminum alloys. This large thickness of compression could give a great increase in fatigue resistance. Other main results with respect to the employed process parameters are given below.

The affected depth was increased with the indenter size increasing from $\emptyset 3$ to $\varnothing 8 \mathrm{~mm}$ but was almost independent of the overlap between dimples which varied from $0 \%$ to $50 \%$.

The induced residual stress fields were anisotropic, characterized by a larger compressive residual stress transverse to indent lines (maximum -360 MPa) and a lower compressive stresses parallel to indent lines $(\max -270 \mathrm{MPa})$. This could result in a variation of fatigue properties with sample direction. The stress anisotropy was hardly affected by the indenter size but increased with increased dimple overlap.

Reducing the distance between dimples improved the surface roughness. The best surface finish, $\mathrm{Ra}<1 \mu \mathrm{m}$, was found with the treatment using the $\emptyset 8 \mathrm{~mm}$ indenter with $50 \%$ dimple overlap.

\section{References}

[1] K.A. Soady, Life assessment methodologies incoroporating shot peening process effects: Mechanistic consideration of residual stresses and strain hardening: Part 1 - Effect of shot peening on fatigue resistance, Mater. Sci. Technol. $29 \quad$ (2013) 637-651. http://dx.doi.org/10.1179/1743284713Y.0000000222

[2] A.T. Bozdana, On the mechanical surface enhancement techniques in aerospace industry - A review of technology, Aircr Eng Aerosp Technol. $77 \quad$ (2005) 279-292. http://dx.doi.org/10.1108/00022660510606349

[3] M. Benedetti, V. Fontanari, P. Scardi, C.L.A. Ricardo, M. Bandini, Reverse bending fatigue of shot peened 7075-T651 aluminium alloy: The role of residual stress relaxation, Int. J. Fatigue. 31 (2009) 1225-1236. http://dx.doi.org/10.1016/j.ijfatigue.2008.11.017

[4] W. Zinn, B. Scholtes, Mechanical Surface Treatments of Lightweight Materials - Effects on Fatigue Strength and Near-Surface Microstructures, J Mater Eng Perform. 8 (1999) 145-151. http://dx.doi.org/10.1361/105994999770346972

[5] L. Wagner, Mechanical surface treatments on titanium, aluminum and magnesium alloys, Mater. Sci. Eng. A. 263 (1999) 210-216. http://dx.doi.org/10.1016/S0921-5093(98)01168-X

[6] I.C. Noyan, J.B. Cohen, Residual Stress Measurement by Diffraction and Interpretation, SpringerVerlag, (1987). 